\title{
Poor precompetitive sleep habits, nutrients' deficiencies, inappropriate body composition and athletic performance in elite gymnasts
}

\author{
M.-R. G. SILVA ${ }^{1,2,3,4} \&$ T. PAIVA ${ }^{1,5}$ \\ ${ }^{1}$ Institute of Molecular Medicine, Medical Faculty of Lisbon, Lisbon, Portugal, ${ }^{2}$ Faculty of Health Sciences, University \\ Fernando Pessoa, Oporto, Portugal, ${ }^{3}$ Research Centre for Anthropology and Health, University of Coimbra, Coimbra, Portugal, \\ ${ }^{4}$ Scientific Commission of the National School of Gymnastics, Gymnastics Federation of Portugal, Lisbon, Portugal, ${ }^{5}$ CENC, \\ Sleep Medicine Center, Lisbon, Portugal
}

Corresponding author:

M.-R. G. Silva, Rua Carlos da Maia, 296, 4200-150 Oporto, Portugal.

E-mail: raquel@ufp.edu.pt

\begin{abstract}
This study aimed to evaluate body composition, sleep, precompetitive anxiety and dietary intake on the elite female gymnasts' performance prior to an international competition. Sixty-seven rhythmic gymnasts of high performance level were evaluated in relation to sport and training practice, body composition, sleep duration, daytime sleepiness by the Epworth Sleepiness Scale (ESS), sleep quality by the Pittsburgh Sleep Quality Index (PSQI), precompetitive anxiety by the Sport Competition Anxiety Test form A (SCAT-A) and detailed dietary intake just before an international competition. Most gymnasts $(67.2 \%)$ suffered from mild daytime sleepiness, $77.6 \%$ presented poor sleep quality and $19.4 \%$ presented high levels of precompetitive anxiety. The majority of gymnasts reported low energy availability (EA) and low intakes of important vitamins including folate, vitamins $\mathrm{D}, \mathrm{E}$ and $\mathrm{K}$; and minerals, including calcium, iron, boron and magnesium ( $\mathrm{p}<.05$ ). Gymnasts' performance was positively correlated with age $(\mathrm{p}=.001)$, sport practice $(\mathrm{p}=.024)$, number of daily training hours $(\mathrm{p}=.000)$, number of hours of training/week $(\mathrm{p}=.000)$, waist circumference $(\mathrm{WC})(\mathrm{p}=.008)$ and sleep duration $(\mathrm{p}=.005)$. However, it was negatively correlated with $\mathrm{WC} / \mathrm{hip}$ circumference $(\mathrm{p}=.000)$, ESS $(\mathrm{p}=.000)$, PSQI $(\mathrm{p}=.042)$, SCAT-A $(p=.002)$, protein $\mathrm{g} / \mathrm{kg}(\mathrm{p}=.028)$, EA $(\mathrm{p}=.002)$ and exercise energy expenditure $(\mathrm{p}=.000)$. High performance gymnasts presented poor sleep habits with consequences upon daytime sleepiness, sleep quality and low energy availability.
\end{abstract}

Keywords: Sleep duration, sleep quality, daytime sleepiness, energy intake, elite gymnasts

\section{Introduction}

It is currently assumed that physical exercise leads to favourable physiological homeostatic regulation of sleep, is responsible for the intensity of slow wave sleep (Fullagar et al., 2015) and helps to stabilize the circadian rhythm and to reduce daytime sleepiness (Halson, 2014). Furthermore, a good quality and an adequate amount of sleep can ensure significant implications in physical, cognitive, emotional balance (Erlacher, Ehrlenspiel, Adegbesan, \& El-Din, 2011) and in the recovery, while reducing the risk of an overtraining state (Fullagar et al., 2015). A study with 12 soccer players (14 hours/ week of training) and 12 controls (1.5 hours/week of training) with an average age of 16 years found out that athletes had a better sleep efficiency, a better daily performance and less variation in sleep at week days and weekend days than controls (Brand, Beck, Gerber, Hatzinger, \& HolsboerTrachsler, 2010a).

However, recent evidence highlights that athletes may experience a reduced quality and/or duration of sleep (Halson, 2014), especially before a competition (Lastella, Lovell, \& Sargent, 2014a). High performance sports are surrounded by agents causing stress and constraints (high performance demands, different time zones, sleeping in a hotel, feeding routines, precompetitive anxiety and stress), which may affect sleep quality in athletes (Erlacher et al., 2011; Schaal et al., 2011). In addition, it has been observed that adolescent and young adult's sleep shows a clear variation in duration and variability (Maslowsky \& Ozer, 2014); this is caused by the specific maturation period of adolescence and by external factors, among 
which are increasing school and performance demands, high tech gadgets, the need for social interactions and health-related factors (Fullagar et al., 2015). Therefore, disordered sleep can negatively affect athletic performance, namely the task execution and mood states (Lastella et al., 2014a). Although it has been reported that sleep quality and quantity are usually poor prior to competition (Halson, 2014), and coping strategies are certainly required, as demonstrated in boaters, before and during a long distance race (Léger et al., 2008), few studies have evaluated sleep in athletes before a competition (Erlacher et al., 2011; Lastella et al., 2014a; Leeder, Glaister, Pizzoferro, Dawson, \& Pedlar, 2012; Léger et al., 2008; Silva et al., 2012).

On the other hand, in elite athletes, adequate energy availability is mandatory to keep both high performance levels and long term health (Silva \& Paiva, 2014). However, in several female athletes, especially gymnasts, the requirements for a lean body (Michopoulou et al., 2011) introduce an important barrier to the desirable health requirements (Silva \& Paiva, 2014). In spite of that, they are likely to stand prolonged fasting periods, which, taking the example of Ramadan, impact on sports are not likely to have major influence on body composition, but may affect sleep, cognition and performance in the short term (Halson, 2014). Therefore, special attention should be driven to energy and nutritional needs related to growth and development of such young athletes, since gymnasts train intensively from very young ages and maintain that training regime during adolescence and early adulthood (Silva \& Paiva, 2014). Besides the above-mentioned drawback, high performance athletes face also an immune function disturbance with a higher probability of infection; this is enhanced by intense training, deficient nutrition, sleep restriction, travelling and changing daily routines and logistics (Fullagar et al., 2015).

Considering the data collected, it can be suggested that during a competition, young female athletes' performances will be influenced by sleep, nutrition, body composition, anxiety and intense physical exercise. Nevertheless, how these athletes' precompetitive behaviours may relate to their subsequent performance has been greatly unexplored (Lastella et al., 2014a). To date, there has been no study that has investigated these factors in gymnasts during training sessions or a competition event. Therefore, this study aims to evaluate sleep, energy intake, body composition and precompetitive anxiety in high performance athletes of Rhythmic Gymnastics (RG) before an international competition, and to analyse the factors impacting both negatively and positively on their performance.

\section{Methods}

\subsection{Participants}

Sixty-seven rhythmic gymnasts $(18.7 \pm 2.9$ years old $)$ of high performance level (36.6 \pm 7.6 hours of training per week and $11.5 \pm 3.2$ years of $\mathrm{RG}^{\prime}$ experience) were evaluated in order to collect training and competition data, daytime sleepiness and sleep quality, precompetitive anxiety and dietary intake before the FIG World Cup and the RG International Tournament in 2011, which took place in Portugal. In accordance with delegations' arrival, athletes were recruited through personal contacts or through their coaches and volunteered to participate. Study design was approved by the Ethical Committee of Medical Faculty of Lisbon and written informed consent was obtained from all participants with 16 years old or more. Participation in the study depended on gymnasts' own decision.

\subsection{Training and competition data}

Several parameters were obtained: the number of training sessions per week and the number of hours of training sessions per day from which the number of hours of training per week was calculated. Performance was examined using the overall performance ranking of each participant from the published final list of general competition results and ordered from 1 the highest to 67 the lowest. Participants were then divided into two groups: GYM1 $(n=33)$ involving gymnasts with the highest scores in competition and GYM2 $(n=34)$ involving gymnasts with the lowest scores.

\subsection{Body composition}

Body mass (BM) was measured by a digital scale (SECA-872, Hamburg, Germany) to the nearest $0.01 \mathrm{~kg}$ wearing $\mathrm{T}$-shirt and gym shorts before the warming up session. Height was determined with a portable stadiometer (SECA-213, Hamburg, Germany) to the nearest $0.1 \mathrm{~cm}$. Procedures were conducted as recommended by the International Society for the Advancement of Kinanthropometry (Marfell-Jones, 2006). Body mass index (BMI) was calculated as a ratio of weight to the squared height $\left(\mathrm{kg} / \mathrm{m}^{2}\right)$. The waist circumference (WC) was measured with a flexible tape at the end of a normal exhalation at the smallest circumference between the thorax and the hips. The hip circumference (HC) was measured with a flexible tape at the largest circumference on trochanters and Waist/Hip Ratio (WHR) was calculated. Body fat (BF), fat-free mass (FFM) 
and total body water (TBW) were assessed by bioimpedance analysis (TANITABC-545, UK).

\subsection{Sleep}

Daytime sleepiness was measured by the Epworth Sleepiness Scale (ESS) (Johns, 1991) and sleep quality by the Pittsburgh Sleep Quality Index (PSQI) (Buysse, Reynolds, Monk, Berman, \& Kupfer, 1989). The total ESS score can range from

0 (zero) to 24 points. A score between 0 and 9 points is matched as no daytime sleepiness; between 10 and 12 points, mild sleepiness; between 13 and 16 points, moderate sleepiness and; above 17 points, severe sleepiness. The PSQI score ranges from 0 (zero) to 21 points. A total score equal to or less than five points is associated with a good quality of sleep and the total score above 5 is considered poor sleep quality. Bed time and awake time during the week and at weekends were obtained together with subjective sleep duration. Variability was measured by the difference in sleep duration during weekends and week days.

\subsection{Precompetitive anxiety}

The Sport Competition Anxiety Test form A (SCATA) or Illinois Competition Questionnaire was applied. SCAT-A was developed by Martens (1977) to evaluate the trait anxiety in a sport event, generally defined as the precompetitive anxiety; it consists of 15 items, with responses classified as rarely, sometimes and often. A score less than 17 points is considered a reduced level of stress; a score between 17 and 24 points is a moderate level and a high level of stress whenever the score is higher than 24 points.

\subsection{Energy and nutrients assessment}

Participants were asked to record all foods and beverages typically consumed for the 24 hours before the interview, including time of day and meal type. Foods were expressed in household measurements and converted to grams and millilitres for a quantitative analysis. Nutrient data were coded and analysed with Food Processor SQL. Energy, carbohydrates and proteins based on body size, percentage of fat, thiamine, riboflavin, niacin, pantothenic acid, vitamin B-6, folate, vitamin B-12, vitamin A, vitamin $\mathrm{C}$, vitamin $\mathrm{D}$, vitamin $\mathrm{E}$, vitamin $\mathrm{K}$, calcium, iron, boron, magnesium, manganese, phosphorus, zinc, fibre and water were included in the daily dietary analyses. The recommended daily levels of the macronutrients' intake were: $1.2-1.6 \mathrm{~g} / \mathrm{kg} / \mathrm{day}$ of proteins, $6-10 \mathrm{~g} / \mathrm{kg} / \mathrm{day}$ of carbohydrates and a minimum of $55 \%$ and $20-35 \%$ of fat (Rodriguez et al., 2009). The Recommended Dietary Allowances (RDA) from the Food and Nutrition Board/Institute of Medicine (FNB/IM), considering the values of the estimated average requirement, was applied for the micronutrients. The basal metabolic rate (BMR) was calculated using the Cunningham equation, as suggested by the ACSM (Rodriguez et al., 2009). Energy availability (EA) was estimated (Silva \& Paiva, 2014); low energy availability (LEA) was defined as EA $<45 \mathrm{kcal} / \mathrm{kg}$ FFM/day; and a threshold below $30 \mathrm{kcal} / \mathrm{kg}$ FFM/day was also investigated, since it is considered the lowest energy threshold of EA for women (Rodriguez et al., 2009). Exercise energy expenditure (EEE) was calculated using the 2011 Compendium of Physical Activities (Ainsworth et al., 2011). These calculations accounted for exercise duration, the intensity of the gymnastics training and BM, which were collected using a characterization questionnaire.

\subsection{Statistical analysis}

The characteristics of the participants are described with proportions for categorical variables and with mean and standard deviation values for continuous variables. To test differences in training, body composition, energy and macronutrients contribution, sleep characterization and precompetitive anxiety of gymnasts separated by performance groups, t-tests were applied. Spearman correlation coefficient was used to determine associations between categorical and continuous variables; due to the number of subjects evaluated, the significance level used was $1 \%$ $(\mathrm{p}<.01)$. Bivariate correlations were run on continuous measures of demographics, body composition, dietary intake, sleep, anxiety and performance. Regression analysis using an automatic linear regression model, aimed to improve model accuracy, was used in order to evaluate predictors of performance prior to competition. Thus, regression standardized predicted values and residuals were computed iteratively, assuming linear models, and adding variables considered significant by correlation analysis using the forward stepwise multiple regression method. The significance level was 5\% $(\mathrm{p}<.05)$. Data were analysed using IBM SPSS statistical software version 21.0 for Windows (New York, USA).

\section{Results}

Of the 115 gymnasts in competition, the response rate was $58.2 \%$. Participants were from different continents, and thus, from several nationalities, namely: North America, South America, Europe, Asia and 
Oceania. Although most gymnasts travelled across different time zones to compete in an environment that may be both geographically distant and different from the home-base, there was no association between the participants' athletic performance and their country of origin.

Age, sport practice, daily training hours and weekly training hours were significantly greater in GYM1 than in GYM2 (Table I).

During the week, the mean sleep duration was 8 h10 \pm 1 h30 min and most gymnasts (56.7\%) slept less than eight hours, while on weekends, most gymnasts $(64.2 \%)$ presented an appropriate duration of sleep and $35.8 \%$ slept less than eight hours. In an inter-group analysis, GYM2 slept significantly less on weekdays than GYM1 $(p=.020)$, since their bedtime was significantly later $(p=.029)$ and awake time was significantly earlier $(p=.010)$ than GYM1 (Table II). The average score for the ESS was 10.2 \pm 3.1 ; most athletes $(67.2 \%)$ had mild daytime sleepiness and only $19.4 \%$ had normal scores. The average PSQI score was $7.0 \pm 2.54$ and most gymnasts $(77.6 \%)$ had poor sleep quality. Although GYM2 demonstrated on average a mild daytime sleepiness and GYM1 presented no daytime sleepiness $(\mathrm{p}=.001), \quad$ GYM1 showed a significantly poorer quality of sleep than GYM2 ( $p=.038$; Table II).

The nationality influence upon the PSQI and the ESS suggests the dissociation between sleep quality and sleepiness. For most countries, athletes had high mean PSQI values. The best scores (3-5 points) were obtained for Korea, Great Britain, Mexico, Singapore and Slovenia; moderate scores (6-10 points) for Portugal, Russia, Thailand, USA, China, France, Malaysia,
Uzerbaijan, Turkey and Austria and; poor scores for the remainders. For the ESS, the worst scores were observed in the Polish, Russian, Spanish and Brazilian athletes with an average of 13 points, and reasonable scores for the others.

In spite of the fact that both groups had demonstrated moderate levels of precompetitive anxiety, $19.4 \%$ of the athletes presented high levels and significant differences were observed between groups $(\mathrm{p}=.002$; Table II).

Mean intake of protein in GYM2 was considered to be adequate, but mean intakes of carbohydrate were below the recommended levels in both groups in accordance with ADA recommendations (2009) (Table III). In addition, $37.3 \%$ of gymnasts presented EA below $45 \mathrm{kcal} / \mathrm{kg}$ FFM/day $(64.7 \%$ in GYM1 and $84.8 \%$ in GYM2) and $44.8 \%$ of gymnasts demonstrated EA below $30 \mathrm{kcal} / \mathrm{kg}$ FFM/day. Gymnasts from GYM1 presented significantly higher EEE $(p=.005)$, resulting in significantly lower EA than GYM2 $(p=.021)$ (Table III).

The majority of gymnasts reported low and aboveadequate intakes of important vitamins and minerals (FNB/IM, 1999, 2000, 2001, 2011; Table III). In an inter-group analysis, gymnasts did not show significant group differences $(p>.05)$ in micronutrients intake, with exception for calcium $(p=.005)$, phosphorus $(p=.022)$ and zinc $(p=.003$; Table III $)$. Although both groups demonstrated fibre and water below the recommended RDA, significant group differences $(\mathrm{p}<.05)$ were found in fibre intake (FNB/IM, 2005a, 2005b; Table III).

Pearson correlation coefficients $(r)$ indicate that performance was positively correlated with age

Table I. Age, training volume, body composition and dietary intake of gymnasts $(n=67)$, according to performance groups (GYM1: gymnasts with the highest scores in competition and GYM2: gymnasts with the lowest scores in competition)

\begin{tabular}{|c|c|c|c|}
\hline & $\begin{array}{c}\text { GYMI }(\mathrm{n}=33) \\
\text { Mean } \pm \mathrm{s}(\text { min.-max. })\end{array}$ & $\begin{array}{c}\text { GYM2 }(\mathrm{n}=34) \\
\text { Mean } \pm \mathrm{s}(\text { min.-max. })\end{array}$ & $\mathrm{p}$ \\
\hline Age (years) & $19.7 \pm 3.1(16-26)$ & $17.8 \pm 2.2(16-24)$ & $.007^{*}$ \\
\hline Years in sport & $12.4 \pm 3.2(5-18)$ & $10.7 \pm 3.0(4-18)$ & $.028^{*}$ \\
\hline Training (times/week) & $5.9 \pm 0.3(5-6)$ & $5.8 \pm 0.4(5-6)$ & .228 \\
\hline Training (hours/day) & $6.8 \pm 1.2(5-9)$ & $5.8 \pm 1.0(5-8)$ & $.000^{*}$ \\
\hline Training (hours/week) & $40.1 \pm 7.7(25-54)$ & $33.2 \pm 5.7(25-48)$ & $.000^{*}$ \\
\hline $\mathrm{BM}(\mathrm{kg})$ & $47.6 \pm 4.8(36-55)$ & $49.1 \pm 5.0(39-58)$ & .222 \\
\hline Height $(\mathrm{m})$ & $1.66 \pm 0.1(1.51-1.75)$ & $1.67 \pm 0.1(1.58-1.83)$ & .772 \\
\hline BMI $\left(\mathrm{kg} / \mathrm{m}^{2}\right)$ & $17.2 \pm 1.0(14.5-19.03)$ & $17.6 \pm 1.2(14.9-20.2)$ & .102 \\
\hline WC (cm) & $54.8 \pm 3.9(49-67)$ & $56.6 \pm 5.6(48-68)$ & .120 \\
\hline $\mathrm{HC}(\mathrm{cm})$ & $65.4 \pm 6.4(59-87)$ & $71.0 \pm 9.9(57-91)$ & $.009^{*}$ \\
\hline $\mathrm{WC} / \mathrm{HC}$ & $0.8 \pm 0.1(0.6-0.9)$ & $0.8 \pm 0.1(0.7-1.0)$ & $.013^{*}$ \\
\hline $\mathrm{BF}(\%)$ & $9.2 \pm 2.2(6-16)$ & $8.9 \pm 2.0(6-15)$ & .579 \\
\hline FFM (kg) & $30.3 \pm 4.7(27-46)$ & $28.6 \pm 5.5(23-44)$ & .573 \\
\hline BMR (kcal/day) & $1145.3 \pm 102.7(1027.9-1441.3)$ & $1129.7 \pm 121.9(937-1413)$ & .573 \\
\hline TBW (L/day) & $48.2 \pm 2.2(46.1-52.8)$ & $51.5 \pm 6.5(43.3-57.9)$ & .917 \\
\hline
\end{tabular}

Note: BM: body mass, BMI: body mass index, WC: waist circumference, HC: hip circumference, BF: body fat, FFM: fat-free mass, BMR: basal metabolic rate, TBW: total body water.

${ }^{*}$ Performance differences determined by independent-samples $t$ tests, $p<.05$. 
Table II. Sleep characterization and precompetitive stress of gymnasts $(n=67)$ according to performance groups $(G Y M 1$ : gymnasts with the highest scores in competition and GYM2: gymnasts with the lowest scores in competition)

\begin{tabular}{|c|c|c|c|}
\hline & $\begin{array}{c}\text { GYM1 }(\mathrm{n}=33) \\
\text { Mean } \pm \mathrm{s}(\text { min.-max. })\end{array}$ & $\begin{array}{c}\text { GYM2 }(n=34) \\
\text { Mean } \pm \text { s(min.-max. })\end{array}$ & $\mathrm{p}$ \\
\hline Bed time, weekdays & 22 h43 \pm 0 h55 (21 h00-01 h00) & 23 h18 \pm 01 h13 $(21$ h30-02 h30) & $.029^{*}$ \\
\hline Bed time, weekend days & 00 h34 \pm 0 h43 (23 h00-01 h30) & 00 h51 \pm 1 h48 (00 h19-03 h00) & .562 \\
\hline Awake time, weekdays & 7 h26 \pm 0 h36 (06 h58-08 h00) & 06 h52 \pm 0 h14 (06 h00-07 h19) & $.010^{*}$ \\
\hline Awake time, weekend days & 08 h05 \pm 1 h16 $(07$ h40-10 h00 $)$ & 07 h49 \pm 0 h55 (06 h00-09 h00) & .611 \\
\hline Sleep, weekdays & 8 h30 \pm 1 h24 (7 h00-9 h30) & 7 h41 \pm 1 h25 (6 h00-9 h30) & $.020^{*}$ \\
\hline Sleep, weekend days & 8 h32 \pm 1 h11 (7 h00-9 h00 $)$ & 8 h $27 \pm 1$ h18 $(7$ h00 -9 h00 $)$ & .770 \\
\hline ESS & $9.0 \pm 0.8(6-10)$ & $11.5 \pm 3.9(8-18)$ & $.001^{*}$ \\
\hline PSQI & $7.7 \pm 2.5(2-12)$ & $6.4 \pm 2.4(3-11)$ & $.038^{*}$ \\
\hline SCAT-A & $21.5 \pm 2.7(13-25)$ & $23.8 \pm 3.2(19-30)$ & $.002^{*}$ \\
\hline
\end{tabular}

Note: ESS: Epworth Sleepiness Scale, PSQI: Pittsburgh Sleep Quality Index, SCAT-A: Sport Competition Anxiety Test form A.

${ }^{*}$ Performance differences determined by independent-samples $t$ tests, $\mathrm{p}<.05$.

Table III. Micronutrients intakes of both groups of gymnasts comparing with the RDA from the FNB/IM (GYM1: gymnasts with the highest scores in competition and GYM2: gymnasts with the lowest scores in competition)

\begin{tabular}{|c|c|c|c|c|c|c|c|}
\hline Energy and macronutrients & $\begin{array}{c}\text { GYM1 }(\mathrm{n}=33) \\
\text { Mean } \pm \mathrm{s}(\min .-\max .)\end{array}$ & & & $\begin{array}{c}\text { GYM2 }(\mathrm{n}=34) \\
\text { Mean } \pm \mathrm{s}(\text { min.-max. })\end{array}$ & & & $\mathrm{p}$ \\
\hline Energy (kcal/kg FFM/day) & $60.5 \pm 13.4(35-78)$ & & & $61.0 \pm 17.7(30-91)$ & & & .898 \\
\hline Carbohydrate (g/kg/day) & $5.5 \pm 2.0(2.2-12.1)$ & & & $4.8 \pm 2.5(1.5-11.5)$ & & & .180 \\
\hline Protein $(\mathrm{g} / \mathrm{kg} /$ day $)$ & $1.7 \pm 0.4(1.2-2.8)$ & & & $1.4 \pm 0.4(0.8-2.4)$ & & & $.001^{*}$ \\
\hline Fat (\%/day) & $33.7 \pm 4.5(20-42)$ & & & $32.3 \pm 5.9(16-43)$ & & & .262 \\
\hline EA (kcal/kg FFM/day) & $29.7 \pm 12.1(21-52)$ & & & $32.3 \pm 11.6(16-59)$ & & & $.021^{*}$ \\
\hline EI (kcal/day) & $1807.6 \pm 232.2(1114-2089)$ & & & $1726.6 \pm 338.6(1047-2320)$ & & & .257 \\
\hline $\mathrm{EEE}$ (kcal/day) & $873.7 \pm 243.9(479-1370)$ & & & $708.6 \pm 217.4(445-1186)$ & & & $.005^{*}$ \\
\hline Micronutrients & Mean $\pm \mathrm{s}$ & RDA & $\mathrm{p}$ & Mean $\pm \mathrm{s}$ & RDA & $\mathrm{p}$ & $\mathrm{p}$ \\
\hline Thiamine (mg/day) & $1.9 \pm 0.8$ & 1.1 & .000 & $2.0 \pm 1.4$ & 1.0 & .001 & .449 \\
\hline Riboflavin (mg/day) & $2.3 \pm 1.0$ & 1.1 & .000 & $2.4 \pm 1.7$ & 1.0 & .000 & .246 \\
\hline Niacin (mg/day) & $23 \pm 13$ & 14 & .000 & $27 \pm 19$ & 14 & .000 & .397 \\
\hline Pantothenic acid (mg/day) & $5 \pm 2$ & 5 & .000 & $4 \pm 0.9$ & 5 & .000 & .065 \\
\hline Vitamin B-6 (mg/day) & $2.1 \pm 1.2$ & 1.3 & .001 & $2.5 \pm 2.0$ & 1.2 & .000 & .350 \\
\hline Folate ( $\mu \mathrm{g} /$ day $)$ & $262 \pm 206$ & 400 & .009 & $348 \pm 372$ & 400 & .02 & .585 \\
\hline Vitamin B-12 ( $\mu \mathrm{g} /$ day) & $4.1 \pm 1.6$ & 2.4 & .000 & $4.1 \pm 2.0$ & 2.4 & .000 & .476 \\
\hline Vitamin $A(\mu \mathrm{g} /$ day $)$ & $1411 \pm 972$ & 700 & .000 & $1500 \pm 1416$ & 700 & .001 & .182 \\
\hline Vitamin C (mg/day) & $90 \pm 49$ & 75 & .000 & $80 \pm 57$ & 65 & .000 & .537 \\
\hline Vitamin D ( $\mu \mathrm{g} /$ day $)$ & $3 \pm 2$ & 15 & .000 & $3 \pm 3$ & 15 & .000 & .688 \\
\hline Vitamin E (mg/day) & $8 \pm 3$ & 15 & .000 & $6 \pm 1$ & 15 & .000 & .349 \\
\hline Vitamin $\mathrm{K}(\mu \mathrm{g} /$ day $)$ & $17.8 \pm 9.6$ & 90 & .000 & $13.9 \pm 7.5$ & 75 & .000 & .549 \\
\hline Calcium (mg/day) & $884 \pm 246$ & 1000 & .000 & $686 \pm 239$ & 1300 & .000 & $.005^{\mathrm{b}}$ \\
\hline Iron $(\mathrm{mg} /$ day $)$ & $13 \pm 8$ & 18 & .001 & $14 \pm 11$ & 15 & $.299^{\mathrm{a}}$ & .537 \\
\hline Boron (mg/day) & $5 \pm 3$ & 20 & .000 & $6 \pm 4$ & 17 & .000 & .176 \\
\hline Magnesium (mg/day) & $293 \pm 98$ & 310 & $.061^{\mathrm{a}}$ & $222 \pm 97$ & 360 & .002 & .229 \\
\hline Manganese (mg/day) & $3.4 \pm 6.6$ & 1.8 & .041 & $2.7 \pm 1.8$ & 1.6 & .021 & .171 \\
\hline Phosphorus (mg/day) & $1301 \pm 658$ & 700 & $\begin{array}{l}.041 \\
.000\end{array}$ & $1059 \pm 289$ & 1250 & $.293^{\mathrm{a}}$ & $.022^{\mathrm{b}}$ \\
\hline Zinc (mg/day) & $12 \pm 5$ & 8 & .001 & $11 \pm 6$ & 9 & .001 & $.003^{\mathrm{b}}$ \\
\hline Fibre (g/day) & $5 \pm 2$ & 25 & .000 & $13 \pm 6$ & 26 & .000 & $.024^{\mathrm{b}}$ \\
\hline Water (L/day) & $1.5 \pm 0.4$ & 2.7 & .000 & $1.4 \pm 0.4$ & 2.3 & .000 & .151 \\
\hline
\end{tabular}

Note: EA: energy availability, EI: energy intake, EEE: exercise energy expenditure.

The data do not include vitamin and mineral supplements.

${ }^{a}$ No significant differences were observed between minerals and the RDA ( $\left.p>05\right)$.

${ }^{b}$ Significant differences were observed in micronutrients intakes between the two groups of gymnasts $(\mathrm{p}<.05)$.

${ }^{*}$ Performance differences determined by independent-samples $t$ tests, $p<.05$. 
Table IV. Linear regression analysis for the prediction of participants' performance

\begin{tabular}{|c|c|c|c|c|c|}
\hline & $\mathrm{R}^{2}$ adjusted & $\mathrm{F}$ & B & SE of B & $\beta$ \\
\hline Model 1 & .454 & $55.801^{* *}$ & 103.137 & 9.421 & \\
\hline Training hours & & & 11.003 & 1.473 & $.680^{* *}$ \\
\hline Model 2 & .571 & $44.838^{* *}$ & 74.394 & 10.676 & \\
\hline Training hours/day & & & 10.077 & 1.323 & $.622^{* *}$ \\
\hline ESS & & & -2.239 & 0.518 & $-.353^{* *}$ \\
\hline Model 3 & .625 & $37.689^{\star *}$ & 85.930 & 10.601 & \\
\hline Training hours/day & & & 9.957 & 1.237 & $.615^{\star *}$ \\
\hline ESS & & & -2.308 & 0.484 & $-.364^{* *}$ \\
\hline PSQI & & & -1.853 & 0.577 & $-.242^{*}$ \\
\hline Model 4 & .650 & $31.680^{* *}$ & 107.199 & 13.663 & \\
\hline Training hours/day & & & 9.210 & 1.236 & $.569^{* *}$ \\
\hline ESS & & & -2.127 & 0.474 & $-.336^{* *}$ \\
\hline PSQI & & & -1.971 & 0.559 & $-.258^{* *}$ \\
\hline Age & & & 1.242 & 0.528 & $.181^{*}$ \\
\hline Model 5 & .671 & $27.950^{\star *}$ & 148.130 & 22.667 & \\
\hline Training hours/day & & & 8.345 & 1.260 & $.515^{\text {* }}$ \\
\hline ESS & & & -1.917 & 0.469 & $-.303^{* *}$ \\
\hline PSQI & & & -1.853 & 0.545 & $-.242^{* *}$ \\
\hline Age & & & 1.280 & 0.512 & $.187^{\star}$ \\
\hline EA & & & -53.947 & 24.243 & $-.171^{*}$ \\
\hline Model 6 & .702 & $26.898^{* *}$ & 121.329 & 23.763 & \\
\hline Training hours/day & & & 7.444 & 1.246 & $.460^{* *}$ \\
\hline ESS & & & -1.963 & 0.447 & $-.310^{* *}$ \\
\hline PSQI & & & -1.493 & 0.536 & $-.195^{\star}$ \\
\hline Age & & & 1.168 & 0.490 & $.171^{*}$ \\
\hline EA & & & -66.808 & 23.572 & $-.212^{*}$ \\
\hline Sleep duration & & & 3.026 & 1.122 & $.197^{\star}$ \\
\hline Model 7 & .730 & $26.518^{* *}$ & 126.171 & 22.677 & \\
\hline Training hours/day & & & 7.247 & 1.187 & $.448^{* *}$ \\
\hline ESS & & & -1.938 & 0.426 & $-.306^{* *}$ \\
\hline PSQI & & & -1.093 & 0.531 & $-.143^{\star}$ \\
\hline Age & & & 0.694 & 0.498 & .101 \\
\hline EA & & & -76.332 & 22.700 & $-.242^{* *}$ \\
\hline Sleep duration & & & 3.653 & 1.093 & $.237^{\star *}$ \\
\hline Protein (g/kg/day) & & & -9.711 & 3.595 & $-.193^{*}$ \\
\hline
\end{tabular}

Note: ESS: Epworth Sleepiness Scale, PSQI: Pittsburgh Sleep Quality Index, EA: energy availability.

${ }^{*} \mathrm{p}<.05$.

${ }^{* *} \mathrm{p}<.001$.

$(\mathrm{r}=.385, \mathrm{p}=.001)$, sport practice $(\mathrm{r}=.276, \mathrm{p}=.024)$, number of daily training hours $(\mathrm{r}=.680, \mathrm{p}=.000)$, number of hours of training/week $(\mathrm{r}=.678, \mathrm{p}=.000)$, WC $(r=.320, p=.008)$ and sleep duration $(r=.339$, $\mathrm{p}=.005)$.

On the other hand, performance was negatively correlated with $\mathrm{WC} / \mathrm{HC}(\mathrm{r}=-.454, \mathrm{p}=.000)$, ESS $(\mathrm{r}=-.454, \mathrm{p}=.000), \quad$ PSQI $\quad(\mathrm{r}=-.242, \mathrm{p}=.042)$, SCAT-A $(\mathrm{r}=-.374, \mathrm{p}=.002)$, protein $\mathrm{g} / \mathrm{kg} \quad(\mathrm{r}=$ $-.269, \mathrm{p}=.028)$, EA $(\mathrm{r}=-.369, \mathrm{p}=.002)$ and $\mathrm{EEE}$ $(\mathrm{r}=-.599, \mathrm{p}=.000)$.

In order to evaluate possible predictors of performance prior to competition, a logistic regression analysis was performed, as mentioned before. Training hours per week, precompetitive anxiety and sport practice were excluded by this statistical method, since they were not significant predictors of the participants' performance. Seven models were found and the last one was the best in

explaining $73 \%$ of the variance in gymnasts' performance $(\mathrm{F}=26.518, \mathrm{p}<.001$; Table IV). Performance was then dependent on daily training hours, ESS, PSQI, age, EA, sleep duration and protein according to body size, as shown in the estimated linear model equation: Gymnasts' performance = $126.171+(7.247 \times$ Daily training hours $)$ $(1.938 \times \mathrm{ESS})-(1.093 \times \mathrm{PSQI})+(0.694 \times$ Age $)-$ $(76.332 \times \mathrm{EA})+(3.653 \times$ Sleep duration $)$ $(9.711 \mathrm{x} \times$ Protein per $\mathrm{g} / \mathrm{kg} / \mathrm{day})$.

\section{Discussion}

In spite of considering sleep as an important resource for the athletes' success, there is a lack of published studies on athletes' sleep (Halson, 2014) and even fewer before competition (Erlacher et al., 2011). This is the first study evaluating sleep duration, 
sleep quality and daytime sleepiness on gymnasts just before (between 1 and 4 days) an international competition. Other authors evaluated sleep habits of other various athletes before competition (Erlacher et al., 2011; Juliff, Halson, \& Peiffer, 2015; Lastella et al., 2014a; Lastella et al., 2014b; Silva et al., 2012). Despite differences in the mentioned studies, namely concerning nationality, athletes category, sportive modality, location and timing of the study, the similarity of results in what concerns bad sleep quality and high proportions of athletes daytime sleepiness is impressive.

Our study, due to its characteristics, as it involved evaluation during a competition of international athletes of multiple nationalities prevented the use of a control population. Thus, normative data are used as reference. Taking into account the competition context, objective body composition data and standard sleep, stress-related and nutrition questionnaires were used. The participants' response rate, in view of the specific competition environment, is adequate; in addition, the number of gymnasts studied is higher than in most published data.

Intensive physical exercise can improve sleep and psychological aspects of adolescent athletes as reported in the literature (Brand et al., 2010a). In fact, these authors observed 12 soccer players and 12 controls with an average age of 16 years, and found out that athletes had better sleep efficiency, better daily performance than controls and less variation in sleep at week days and weekend days.

We demonstrate a considerable inconsistency in the actual intensive sportive practice. In our study $80.7 \%$ of the gymnasts had abnormal ESS scores and $77.6 \%$ abnormal PSQI values; these values are very similar to the $83.3 \%$ found in Paralympic athletes in the period preceding competition (Silva et al., 2012). Erlacher et al. (2011) administered a questionnaire to 632 German athletes, where they had reported their sleep habits before an important competition in the preceding 12 months. Only $27.4 \%$ showed an increased daytime sleepiness, but athletes' level of competition (national or international) was not mentioned. Indeed, most gymnasts travelled across different time zones to compete in an environment that may be both geographically distant and different from the home-base, which can have impact on sleep patterns (Erlacher et al., 2011; Halson, 2014; Schaal et al., 2011). It seems that the general finding from sleep medicine that athletes who compete at an international level can suffer more from sleep disruptions is reflected by our results.

Taking this data into consideration one must assume differences between individual and team sportive modalities and between the physical requirements of each modality, namely athletic versus lean body. Indeed, gymnasts from our study presented low $\mathrm{BF}$, which was below the minimum recommended level of $12 \%$ compatible with health for female athletes, as recently published (Rodriguez et al., 2009; Silva \& Paiva, 2014).

Although athletes' sleep patterns are unclear due to athletes and competition characteristics, our study showed that the duration of sleep was reduced ( $<8$ hours) in $56.7 \%$ of the cases, considering the recommended amounts for gymnasts' age (Fullagar et al., 2015). The pattern obtained for sleep variability during the weekdays and at weekends was different from what is normally obtained for adolescents and young adults; in fact, the difference on sleep duration between week and weekend was approximately 30 minutes $(29.9 \%$ of the athletes slept less even during weekends), lower than cited in the literature for adolescents (Maslowsky \& Ozer, 2014). Furthermore, the inter-subject variability was higher during week days when compared to weekends. This suggests strict time and work schedules for these athletes, with many training sessions also during Saturdays.

In adolescents and young adult studies concerning sleep duration a decrease in sleep duration with age is currently observed (Maslowsky \& Ozer, 2014). This was not the case of our participants, suggesting a high burden in terms of training, habits and responsibility for the younger ones $(53.7 \%$ of the girls were 18 years old or younger).

Gymnasts' performance was, as expected, negatively correlated with PSQI showing the presence of sleep disturbance in winners and the lack of it in athletes with worse scores. Aesthetic athletes such as gymnasts, professional dancers and synchronized swimmers train and compete in conditions of extreme physical and mental stress (Fietze et al., 2009); moreover, training hours are usually based on logistics rather than on physiological aspects of the human body. Thus, athletes cannot rest sufficiently, they have irregular chronobiological sleepwake rhythm (Fietze et al., 2009), low EA, unbalanced contribution of macronutrients, and micronutrients, stress and low BMI for their age (Silva \& Paiva, 2014). In fact, Brand et al. (2010b) found out that female athletes, who weekly spent

17.7 hours exercising, had a worse quality of sleep $(5.2 \pm 1.1)$ when compared with controls (4.9 \pm 1.2). The average training time in our study was two times higher (36.6 hours/week, ranging from 25 to 54 hours).

On the other hand, gymnasts' performance was positively correlated with sleep duration may be due to a longer sleep duration in some gymnasts $(34.3 \%$ 
sleeping nine hours or more). It is evident that gymnasts with worse scores clearly suffered from mild daytime sleepiness, since their sleep duration was significantly lower than gymnasts with the best scores.

The relations with athletic performance and anxiety results show the possible deleterious effects of sleepiness upon performance and the need of successful coping strategies, specifically in GYM2, who were younger and reported less sport experience than GYM1. Athletes from aesthetic and individual sports are more likely to be affected by anxiety Sachaal et al. (2011) and normally present more sleep problems than athletes from team sports (Erlacher et al., 2011). Since our participants meet both of the mentioned criteria, coping strategies may be implemented, such as listening to their favourite music during training sessions (Dekker, Van den Berg, Denissen, Sitskoorn, \& Van Boxtel, 2014) and a brief nap after lunch, if a training session or a competition event is going to be completed in the afternoon or evening (Halson, 2014).

Gymnasts' performance was negatively correlated with EA, since significantly LEA were observed in gymnasts with the best scores may be due to their higher EEE during training sessions and competition demands. These findings may compromise gymnasts' energy needs for growth, maturation and athletic performance (Silva \& Paiva, 2014) and increase the risk for developing health and physical performance hazards, such as negative musculoskeletal effects, bone stress injuries and low bone-mineral density. Thus, it is clear that an individualized nutritional assessment is required in order to ensure athletes' immune and reproductive functions, bone health and performance (Silva \& Paiva, 2014). One of two resolution strategies for this LEA should be addressed: increase EA by increasing EI or decrease EEE by reducing training volume.

Athletes' micronutrient intake was in general higher in gymnasts with the best scores. However, both age groups had significantly inadequate intakes of essential micronutrients that may impact on their growth and maturation, skeletal development and reproductive function, with the exception of magnesium intake (Silva \& Paiva, 2014), which was within the optimal range in GYM1, and of iron (Michopoulou et al., 2011; Silva \& Paiva, 2014) and phosphorus intake (Silva \& Paiva, 2014) in GYM2. The significantly low levels of iron $(p=.299)$ in GYM2 may conduct these athletes to the presence of anaemia (Michopoulou et al., 2011). Although gymnasts did not report the consumption of beverages containing carbohydrates or electrolytes before, during or after training sessions, deficits in water and fibre consumption were surprisingly observed. Therefore, these athletes should be encouraged to drink enough fluid before, during and after physical exercise, and to eat fruits, vegetables and whole grains in order to minimize gastrointestinal distress and to regulate appetite.

The limitations of this study should be taken into account when interpreting these results. Sleep evaluation including either polysomnography or actigraphy would be a better assessment method, but both are unpractical during a competition (Fullagar et al., 2015; Halson, 2014) and subjective and polysomnographic assessments of sleep have reached the same conclusions (Brand et al., 2010a; Werner, Molinari, Guyer, \& Jenni, 2008). Although estimating dietary intakes is difficult especially prior to a competition, gymnasts were motivated and willing to reliably report habitual intake. In order to verify the problem of underreporting food intake, the minimum level of energy expenditure of $1251 \mathrm{kcal}$ was observed, suggesting that daily EI underestimation might have been avoided (Silva \& Paiva, 2014). The insufficient fluid intake reported by gymnasts or a greater requirement due to intensive training routines can be linked to the reduction of their TBW (Silva \& Paiva, 2014). Although bioelectrical impedance can provide fairly accurate estimates of TBW and FFM (Rodriguez et al. (2009), it depends on a number of factors that can cause error in the measurement (e.g. hydration status may alter the estimated percentage BF). Therefore, a gold standard measurement to determine the athletes' hydration status - urine osmolality should be measured using a handheld refractometer in future studies. It is also important to note the potential for an inflated risk of type 1 error in this study due to multiple t-tests and multiple correlations.

\section{Conclusions}

High performance rhythmic gymnasts presented low $\mathrm{BF}$, poor sleep habits with consequences upon daytime sleepiness, sleep quality and LEA associated with macro and micronutrients' deficiencies. Participating in high performance sports gives increased responsibility to the young gymnasts and certainly high levels of satisfaction and personal achievement, but the present and future impact upon sleep, general health and lifetime achievements require systematic research.

\section{Acknowledgements}

This work was carried out at the Institute of Molecular Medicine, Medical Faculty of Lisbon, Lisbon, Portugal. This research did not receive any specific grant from any funding agency in the public, commercial or not-profit sector. Both authors were responsible for the conception, design, data analysis 
and data interpretation of the study and writing the manuscript; M.-R. G. Silva was also responsible for data collection. Authors would like to thank the gymnasts for their participation in this study and the coaches for their cooperation. The authors are also grateful to the editor and reviewers for their valuable comments.

\section{Disclosure statement}

No potential conflict of interest was reported by the authors.

\section{References}

Ainsworth, B. E., Haskell, W. L., Herrmann, S. D., Meckes, N., Bassett, D. R. Jr., Tudor-Locke, C., ... Leon, A. S. (2011). Compendium of physical activities: A second update of codes and MET values. Medicine \& Science in Sports \& Exercise, 43(8), 1575-1581. doi:10.1249/MSS.0b013e31821ece12

Brand, S., Beck, J., Gerber, M., Hatzinger, M., \& HolsboerTrachsler, E. (2010a). Evidence of favorable sleep-EEG patterns in adolescent male vigorous football players compared to controls. World Journal of Biological Psychiatry, 11, 465-475. doi:10.1080/15622970903079820

Brand, S., Gerber, M., Beck, J., Hatzinger, M., Pühse, U., \& Holsboer-Trachsler, E. (2010b). High exercise levels are related to favorable sleep patterns and psychological functioning in adolescents: A comparison of athletes and controls. Journal of Adolescent Health, 46, 133-141. doi:10.1016/j.jadohealth.2009. 06.018

Buysse, D. J., Reynolds, C. F., Monk, T. H., Berman, S. R., \& Kupfer, D. J. (1989). The Pittsburgh sleep quality index: A new instrument for psychiatric practice and research. Psychiatry Research, 28, 193-213. doi:10.1016/0165-1781(89) 90047-4

Dekker, M. K. J., Van den Berg, B. R., Denissen, A. J. M., Sitskoorn, M. M., \& Van Boxtel, G. J. M. (2014). Feasibility of eyes open alpha power training for mental enhancement in elite gymnasts. Journal of Sports Sciences, 32, 1550-1560. doi:10.1080/02640414.2014.906044

Erlacher, D., Ehrlenspiel, F., Adegbesan, O. A., \& El-Din, H. G. (2011). Sleep habits in German athletes before important competitions or games. Journal of Sports Sciences, 29, 859-866. doi:10.1080/02640414.2011.565782

Fietze, I., Strauch, J., Holzhausen, M., Glos, M., Theobald, C., Lehnkering, H., \& Penzel, T. (2009). Sleep quality in professional ballet dancers. Chronobiology International, 26, 12491262. doi:10.3109/07420520903221319

Food and Nutrition Board/Institute of Medicine. (1999). Dietary reference intakes for thiamin, riboflavin, niacin, vitamin B6, folate, vitamin B12, pantothenic acid, biotin, and choline. Washington, DC: National Academies Press. Retrieved from http://www.nap.edu/catalog.php?record_id=6015

Food and Nutrition Board/Institute of Medicine. (2000). Dietary reference intakes for vitamin $\mathrm{C}$, vitamin $\mathrm{E}$, selenium, and carotenoids. Washington, DC: National Academies Press. Retrieved from http://www.nap.edu/catalog.php?record_id=9810

Food and Nutrition Board/Institute of Medicine. (2001). Dietary reference intakes for vitamin $\mathrm{A}$, vitamin $\mathrm{K}$, arsenic, boron, chromium, copper, iodine, iron, manganese, molybdenum, nickel, silicon, vanadium, and zinc. Washington, DC: National Academies Press. Retrieved from http://www.nap.edu/catalog/ 10026.html
Food and Nutrition Board/Institute of Medicine. (2005a). Dietary reference intakes for energy, carbohydrate, fiber, fat, fatty acids, cholesterol, protein and amino acids. Washington, DC: National Academies Press. Retrieved from http://www.nap.edu/catalog. php?record_id=10490

Food and Nutrition Board/Institute of Medicine. (2005b). Dietary reference intakes for water, potassium, sodium, chloride, and sulfate. Washington, DC: National Academies Press. Retrieved from http://www.nap.edu/catalog/10925.html

Food and Nutrition Board/Institute of Medicine. (2011). Dietary reference intakes for calcium and vitamin D. Washington, DC: National Academies Press. Retrieved from http://www.nap. edu/catalog.php?record_id=13050

Fullagar, H. H., Skorski, S., Duffield, R., Hammes, D., Coutts, A. J., \& Meyer, T. (2015). Sleep and athletic performance: The effects of sleep loss on exercise performance, and physiological and cognitive responses to exercise. Sports Medicine, 45, 161186. doi:10.1007/s40279-014-0260-0

Halson, S. L. (2014). Sleep in elite athletes and nutritional interventions to enhance sleep. Sports Medicine, 44, 13-23. doi:10. 1007/s40279-014-0147-0

Johns, M. W. (1991). A new method for measuring daytime sleepiness: The Epworth sleepiness scale. Sleep, 14, 540-545. PMID: 1798888

Juliff, L. E., Halson, S. L., \& Peiffer, J. J. (2015). Understanding sleep disturbance in athletes prior to important competitions. Journal of Science and Medicine in Sport, 18, 13-18. doi:10. 1016/j.jsams.2014.02.007

Lastella, M., Lovell, G. P., \& Sargent, C. (2014a). Athletes' precompetitive sleep behaviour and its relationship with subsequent precompetitive mood and performance. European Journal of Sports Sciences, 14, S123-S130. doi:10.1080/ 17461391.2012.660505

Lastella, M., Roach, G. D., Halson, S. L., Martin, D. T., West, N. P., \& Sargent, C. (2014b). Sleep/wake behaviour of endurance cyclists before and during competition. Journal of Sports Sciences, 33, 293-299. doi:10.1080/02640414.2014.942690

Leeder, J., Glaister, M., Pizzoferro, K., Dawson, J., \& Pedlar, C. (2012). Sleep duration and quality in elite athletes measured using wristwatch actigraphy. Journal of Sports Sciences, 30, 541-545. doi:10.1080/02640414.2012.660188

Léger, D., Elbaz, M., Raffray, T., Metlaine, A., Bayon, V., \& Duforez, F. (2008). Sleep management and the performance of eight sailors in the Tour de France a la voile yacht race. Journal of Sports Sciences, 26, 21-28. doi:10.1080/02640410701348636

Marfell-Jones, M. (2006). International standards for anthropometric assessment. South Africa, ISAK: Potchefsroom.

Martens, R. (1977). Sport competition anxiety test. Champaign, IL: Human Kinetics Publishers, Inc.

Maslowsky, J., \& Ozer, E. J. (2014). Developmental trends in sleep duration in adolescence and young adulthood: Evidence from a national United States sample. Journal of Adolescent Health, 54, 691-697. doi:10.1016/j.jadohealth.2013.10.201

Michopoulou, E., Avloniti, A., Kambas, A., Leontsini, D., Michalopoulou, M., Tournis, S., \& Fatouros, I. G. (2011). Elite premenarcheal rhythmic gymnasts demonstrate energy and dietary intake deficiencies during periods of intense training. Pediatric Exercise Science, 23, 560-72. PMID:22109784

Rodriguez, N. R., DiMarco, N. M., Langley, S., American Dietetic Association, Dietitians of Canada, \& American College of Sports Medicine. (2009). Position of the American Dietetic Association, Dietitians of Canada and the American College of Sports Medicine: Nutrition and Athletic Performance. Journal of the American Dietetic Association, 109, 509-27. doi:10.1016/j.jada.2009.01.005

Schaal, K., Tafflet, M., Nassif, H., Thibault, V., Pichard, C., Alcotte, M., ... Toussaint, J. F. (2011). Psychological balance 
in high level athletes: Gender-based differences and sportspecific patterns. PLoS One, 6, 1-9. doi:10.1371/journal.pone. 0019007

Silva, A., Queiroz, S. S., Winckler, C., Vital, R., Sousa, R. A., Fagundes, V., ... de Mello, M. T. (2012). Sleep quality evaluation, chronotype, sleepiness and anxiety of Paralympic Brazilian athletes: Beijing 2008 Paralympic Games. British Journal of Sports Medicine, 46, 150-154. doi:10.1136/bjsm.2010.077016
Silva, M.-R. G., \& Paiva, T. (2014): Low energy availability and low body fat of female gymnasts before an international competition. European Journal of Sport Science, 16, 1-9. doi:10.1080/ 17461391.2014.969323

Werner, H., Molinari, L., Guyer, C., \& Jenni, O. G. (2008). Agreement rates between actigraphy, diary, and questionnaire for children's sleep patterns. Archives of Pediatrics and Adolescent Medicine, 162, 350-358. doi:10.1001/archpedi.162.4.350 